\title{
A condition that should be kept in mind in incarcerated hernia: Amyand's hernia
}

\author{
Mehmet Bugra Bozan, ${ }^{1}$ Fatih Mehmet Yazar, ${ }^{1}$ Fatih Erol, ${ }^{1}$ Evrim Gul, ${ }^{2}$ Omer Dogan Alatas ${ }^{2}$ \\ ${ }^{1}$ Department of General Surgery, Elazig Training and Research Hospital, Elazig, Turkey \\ ${ }^{2}$ Department of Emergency Clinic, Elazig Training and Research Hospital, Elazig, Turkey
}

\begin{abstract}
As a complication of inguinal hernia, incarcerations are often seen in emergency services. Incarceration is an acute complication of inguinal hernia presenting as surgical emergency. The sac of inguinal hernia most frequently contains omentum and intestine but sometimes organs such as appendix and Meckel's diverticulum can also be seen in the hernial sac. We present a case of Amyand's hernia containing appendix in the incarcerated herniated sac.
\end{abstract}

Keywords: Amyand's hernia; groin hernia; incarseration.

$\mathrm{E}_{\mathrm{c}}$ mergency cases are an important aspect of surgical practice. Hernia is displacement of intraabdominal tissues and organs through a weak point in the abdominal wall [1]. Incarceration is an acute complication of inguinal hernias. Most common contents of hernial sac include omentum, and intestines but. Cladius Amyand was first to described the presence of an appendix in the hernia sac, a condition coined after him. Amyand's hernia is not very commonly seen condition representing $0.07-0.13 \%$ of all inguinal hernias $[2,3]$. In this paper we describe a case of appendix present in incarcerated inguinal hernia.

\section{CASE REPORT}

A 35-year-old patient who presented at the emergency room with complaints of pain localized to the right inguinal region, nausea, and vomiting for 3 days with no bowel complaints. On physical examination a painful, irreducible swelling was noted on the right inguinal region. Examination of other systems yielded normal results. His lab results showed leucocytosis $\left(13290 / \mathrm{mm}^{3}\right)$. With no other abnormal finding. Plain abdominal radiograms obtained in the standing position did not reveal any pathology. Superficial tissue ultrasound of the inguinal region obtained under emergency conditions detected a hernia sac containing mesenterium, intestinal loopsand a blind-ended tubular structure with a diameter of $6 \mathrm{~mm}$ which was ruled in favor of an appendix.

The patient was operated in emergency preoperatively a single dose of $1 \mathrm{~g}$ cefazolin was administered IV. A right inguinal oblique incision was

This case report was presented at the International Critical Care and Emergency Medicine Congress, held at Istanbul, 06-08 November 2013.

Received: October 11, 2014 Accepted: September 01, 2015 Online: May 10, 2017

Correspondence: Dr. Mehmet Bugra BOZAN. Elazig Egitim ve Arastirma Hastanesi,

Genel Cerrahi Klinigi, 23100 Elazig, Turkey.

Tel: +90 424 - 2381000 e-mail: bbozan@yahoo.com

(c) Copyright 2017 by Istanbul Northern Anatolian Association of Public Hospitals - Available online at www.kuzeyklinikleri.com 


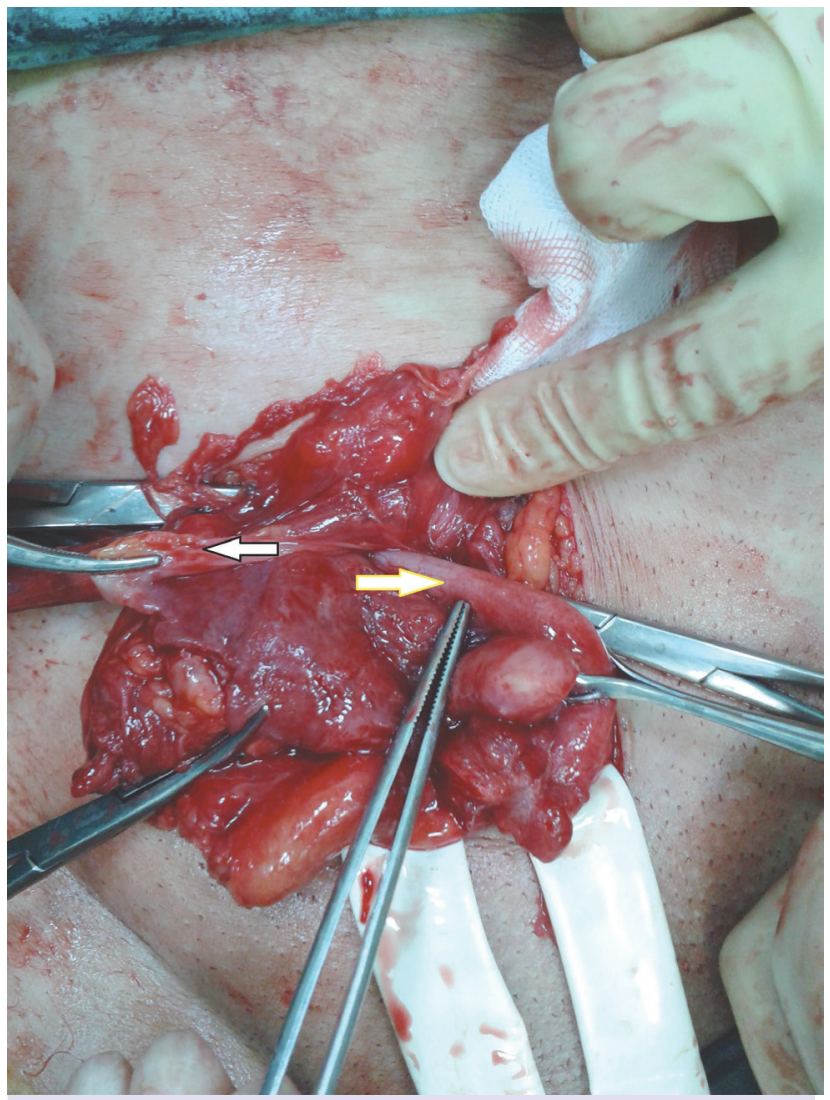

FIGURE 1. Appendix in the hernia sac (white arrow, hernia sac; yellow arrow, appendiceal tissue).

used to isolate the hernia sac. On opening the sac mesentery of appendix was found adherent to the hernia sac along with herniation of appendix and intestinal loops (Figure 1). Appendix was intact (Figure 1). Appendectomy was performed, hernial sac was repaired and Lichtenstein herniorraphy was performed using prolene mesh. The postoperative period was uneventful was patient was discharged in good health.

\section{DISCUSSION}

Incareceration as an acute complication of inguinal hernia is often seen as surgical emergency. Omentum and intestine are common present in the hernia sac but different organs can also be seen in hernia sac (e.g., appendix, Meckel's diverticulum) [4]. Cladius Amyand was first to described the presence of appendix in the inguinal hernia sac, a condition named after him as Amyand's hernia. It is a rare condition constituting $1 \%$ of all types of inguinal hernias and presence of inflamed appendiceal tissue is not a prerequisite for its diagnosis $[2,3]$. In our case also appendiceal tissue was herniated, but not inflammed.

Adhesions formed in the hernia sac causes the appendix to remain in the hernia sac [5]. In our case, herniation of appendiceal tissue was due to retraction of appendiceal mesentery by adhesion formation which pulled the appendix in the sac.

As all inguinal hernias, Amyand's hernia is more frequently observed in males $[3,5]$, our case was also a 35-year-old male patient.

Though definitive diagnosis is generally made during intraoperative period, ultrasound, and abdominal computed tomography can aid in diagnosis preoperatively, as the case presented here [5].

TABLE 1. Types of Amyand's hernia according to Losanoff and Basson, and their treatment [5]

\begin{tabular}{|c|c|c|}
\hline Classification & Definition & Surgical Approach \\
\hline Type 1 & Intact appendix in inguinal hernia sac & $\begin{array}{l}\text { Reduction of inguinal hernia; hernia repair using mesh; } \\
\text { appendectomy in young patients }\end{array}$ \\
\hline Type 2 & $\begin{array}{l}\text { Acute appendicitis in inguinal hernia } \\
\text { sac without abdominal sepsis }\end{array}$ & $\begin{array}{l}\text { Appendectomy through inguinal hernia repair site; } \\
\text { primary repair of the hernia without using mesh }\end{array}$ \\
\hline Type3 & $\begin{array}{l}\text { Acute appendicitis in inguinal hernia sac } \\
\text { and abdominal wall or peritoneal sepsis }\end{array}$ & $\begin{array}{l}\text { Laparatomy, appendectomy, primary } \\
\text { hernia repair without using mesh }\end{array}$ \\
\hline Type4 & $\begin{array}{l}\text { Acute appendicitis in inguinal hernia sac, } \\
\text { and presence of related or unrelaated } \\
\text { abdominal pathology }\end{array}$ & $\begin{array}{l}\text { Apply treatment plans recommended for } \\
\text { Type1-3; in case of need apply any } \\
\text { other necessary treatment modality }\end{array}$ \\
\hline
\end{tabular}


The differential diagnosis of Amyand's hernia and inguinal hernias includes testicular torsion, acute epididymitis, acute hydrocele, and inguinal lymphadenitis.

Treatment options are based on the severity of appendiceal inflammation. Generally, if the appendix is not inflamed, hernia repair can be performed using synthetic mesh. If inflammation is present hernia repair is performed without using synthetic meshes through inguinal or other abdominal incisions as per the recommendations. With this approach, it is thought that potential complications of surgical site infection (SSI), mesh infections, and fistula formation can be prevented. Thus, appendectomy is performed in the presence of inflammation, while in cases without inflammation, appendectomy is debatable. According to Losanof ve Basson if appendiceal inflammation is not present, then reduction of the hernia sac, and in young patients, appendectomy, and hernia repair with synthetic mesh are recommended. Table 1 in our case, since the patient was young, appendectomy was performed despite benign nature of the appendix [5]. Inflammation was not observed herniorrhaphy using mesh was performed.

\section{Conclusion}

Incarcerated inguinal hernias which can confront us in emergency services are among conditions which should be carefully considered. As was seen especially in this case, physician practicing in emergency services, and general surgeons should not overlook the potential presence of different organs such as appendix in incarcerated hernial sac.

Conflict of Interest: None declared.

Financial Disclosure: The authors declared that this study has received no financial support.

Authorship contributions: Concept - M.B.B., F.M.Y., F.E.; Design - M.B.B., F.E.; Supervision - E.G., O.D.A.; Materials M.B.B.; Data collection \&/or processing - M.B.B., E.G.; Analysis and/or interperation: M.B.B., F.E.; Literature search - M.B.B.; Writing - M.B.B.; Critical review - M.B.B., F.M.Y.

\section{REFERENCES}

1. Ersoy E, Tekin E, Condon R. Karın Duvarı Fitıkları. In: Sayek İ (Ed.) Temel Cerrahi. 4. Baskı. Güneş Tıp Kitabevleri: Ankara; 2013: s. 1803-24.

2. Sharma H, Gupta A, Shekhawat NS, Memon B, Memon MA. Amyand's hernia: a report of 18 consecutive patients over a 15 year period. Hernia 2007;11:31-5.

3. Milanchi S, Allins AD. Amyand's hernia: history, imaging, and management. Hernia 2008;12:321-2.

4. Bendavid R. The unified theory of hernia formation. Hernia 2004;8:171-6.

5. Singal R, Gupta S. "Amyand's Hernia" - Pathophysiology, Role of Investigations and Treatment. Maedica (Buchar) 2011;6:321-7. 